\title{
Trusted Teammates: Commercial Digital Games Can Be Effective Trust-Building Tools
}

$\begin{array}{ll}\text { Evelyn Tan } & \text { Anna L Cox } \\ \text { University of York } & \text { University College London } \\ \text { York, YO10 5DD } & \text { London, WC1E 6BT } \\ \text { United Kingdom } & \text { United Kingdom } \\ \text { ett506@york.ac.uk } & \text { anna.cox@ucl.ac.uk }\end{array}$

Permission to make digital or hard copies of part or all of this work for personal or classroom use is granted without fee provided that copies are not made or distributed for profit or commercial advantage and that copies bear this notice and the full citation on the first page. Copyrights for third-party components of this work must be honored. For all other uses, contact the owner/author(s).

CHI'19 Extended Abstracts, October 22-25, 2019, Barcelona, Spain.

Copyright is held by the owner/author(s).

ACM ISBN 978-1-4503-6819-3/20/04.

DOI: https://doi.org/10.1145/3334480.XXXXXXX

\begin{abstract}
Trust is a key component of high functioning virtual work teams. This study investigates the effectiveness of a commercial digital game in developing trust in virtual teams compared to a typical virtual team icebreaker. To achieve this, we outline important trust-building aspects that a game must have and identify the commercial digital game Spaceteam as a suitable candidate. Our results show that Spaceteam is more effective at developing trust in virtual teams compared to social icebreaker, indicated by differences in trusting behaviour. We did not find differences in perception of team trust or moderating effects of dispositional trust. Our findings suggest that digital games with trustbuilding aspects enable the verification of early trusting beliefs through gameplay, which in turn develops trust among team members. As these games are robust against individual differences in dispositional trust, it is applicable across any team composition. Our findings support the use of digital games as viable trust-building tools for virtual work teams.
\end{abstract}

\section{CCS Concepts}

-Applied Computing $\rightarrow$ Computer Games; •Human-

Centered Computing $\rightarrow$ Computer Supported Collaborative Work; 


\section{How to identify a suitable commercial digital game for trust-building}

\section{Corporate use require-} ments [32]:

- Easy to learn.

- Short completion time (i.e. under 30 minutes).

- Draw parallels with the virtual work context.

\section{Trust-building require-} ments:

- Have clear, shared, interdependent goals $[30,31]$. This creates a context of risk and uncertainty and necessitates interaction between players.

- Require team members to plan, strategise and communicate to coordinate their actions. This provides opportunity for swift trust beliefs to be verified [9].

\section{Author Keywords}

Digital Games; Virtual Teams; Trust; Team Effectiveness; Workgroups

\section{Introduction}

Interpersonal trust is the foundation of collaborative, interdependent work in teams and develops over time through repeated interactions $[26,10,18,8]$. It enables risk-taking behaviours such as cooperation, providing help and investing effort because of expectations that these actions will be positively reciprocated $[25,5,16]$. As team members gain more knowledge and information about each other, social bonds develop and trust increases. In virtual work teams, however, trust develops differently. High trust exists prior to the formation of relationships [21, 22, 23, 36]. This form of trust is known as 'swift trust'. Sustaining swift trust during the initial stages of the team is necessary for interpersonal trust to develop during the later stages of the team [19, 9, 17].

The dominant approach to developing interpersonal trust early in the team's life cycle is through social ice breakers. Social icebreakers are thought to help team members get acquainted and develop social bonds [42, 14, 17]. However this approach is limited because it lacks the contextual factors that facilitate trust development - risk and interdependence [34, 35]. Furthermore, the emphasis on personal information exchange does little for verifying swift trust, which is based on presumptions of competence and reliability rather than social bonds.

Research on the viability of digital games as team-building tools has begun to emerge $[15,27,4,32,12,6]$. This interest is driven by the fact that digital games are cost-effective compared to a physical team-building activity, easily deployable, engaging and can be tailored to meet specific team needs. As such, digital games have the potential to provide the contextual factors necessary for trust development. Indeed, a recent study found that a trust-building digital game was more effective than a social icebreaker at developing trust in virtual teams consisting of two individuals [12].

However, their findings have several limitations. For example, only survey measures of trust were used. As stated by [7], trusting behaviours (i.e. cooperating in situations with uncertain reciprocation) distinguish the willingness to be vulnerable to the actions of others from the actual behaviour of becoming vulnerable. Without understanding whether trust-building digital games have an impact on behaviour, it is difficult to recommend the use of these games in the real world. Their study also uses two-person teams.

This does not reflect real-world teams as virtual work teams rarely comprise of only two persons. We address these limitations by using four-person teams and a behavioural measure of trust (i.e. a variant of the Prisoner's dilemma) to supplement survey measures.

We also chose to use a commercial digital game instead of a purpose-built game because organisations are likely to lack the capacity or skill to make their own trust-building game as [12] did. Therefore, it is important to investigate whether commercial digital games can be effective for trustbuilding in virtual work teams. In order to further investigate the effectiveness of digital games in facilitating trust development in virtual teams compared to a social icebreaker, we address the limitations of [12] and identify and test a trust-building commercial digital game for this purpose.

\section{Background}

Digital games as trust-building tools

There are currently two approaches to swift trust development. The first emphasises its development through enthu- 


\section{Icebreaker Activities in}

\section{Each Condition}

Spaceteam: A multiplayer cooperative mobile game.

Players are assigned a random control panel with buttons, switches, sliders and dials. Players have to coordinate to complete timesensitive instructions. These instructions are different for each player and may correspond to either their own or their teammate's control panel. The objective is to progress through as many levels as possible [20]

Hollywood Stars: A typical social icebreaker where individuals state the name of an actor or character they like or identify with. The team has to guess why the individual chose the character. During the study, a list of questions was provided to facilitate the conversation. Participants were required to speak for at least two minutes to ensure they were engaged [14]. siastic social communication at the team's inception [23, 43]. The second relies on actions that reinforce presumptions about competence and reliability [9, 12]. Since swift trust is "not so much an interpersonal form as it a cognitive and action form" [30], we argue that trust-building activities based on the second approach are more effective. Digital games may be viable trust-building tools because they promote certain behaviours through gameplay. For instance, some games need cooperation to achieve game objectives which could facilitate trust development. Furthermore, immediate feedback and a playful environment allow team members to verify and adjust swift trust beliefs in a safe environment.

Measuring the effect of the trust-building tool

As trust has attitudinal and behavioural components [28, 30], we expect:

Hypothesis 1: Perception of team trust (attitude) will be positively related to cooperative behaviour (behaviour).

Hypothesis 2: Teams using Spaceteam will have higher perception of trust (attitude) and higher cooperation (behaviour) compared to teams using Hollywood Stars.

The trust literature states that an individual's dispositional trust affects interpersonal trust [28, 36], even after trustworthiness has been gauged [7], Dispositional trust is the general willingness to trust others [28]. However, [12], on which this study builds on, found no moderating effect of dispositional trust on perception of trust. Hence we expect:

Hypothesis 3: The effect of Spaceteam on cooperation will not be moderated by an individual's dispositional trust.

\section{Method}

Design

This study adopted a between-subjects design. Our independent variables were condition (Spaceteam or Hollywood Stars) and dispositional trust, and our dependent variables were perception of team trust and behavioural trust.

\section{Participants}

Eighty participants (Male $=44$, Female $=36$ ), aged between 20 to 53 years (mean age $=25.64$ ) took part in the study. There were 20 four-person teams, randomly allocated to either the Spaceteam condition or Hollywood Stars condition.

\section{Materials}

General Trust Scale (GTS)

This six-item measure of dispositional trust identifies an individual's general belief about the honesty and trustworthiness of others (e.g. 'most people are basically honest') [41]. The questionnaire is answered on a 5-point Likert scale.

Intrateam Trust Scale (ITS)

This four-item measure of team trust, adapted from [38] assesses group members' perceptions of group-wide trust, their perception of group-wide expectations of truthfulness, integrity and living up to one's word, and their sense of shared respect of group members' competence [25]. The ITS uses a 5-point Likert scale.

\section{Icebreaker Conditions}

Spaceteam was identified as a suitable commercial digital game and Hollywood Stars was identified as a typical social icebreaker used in virtual teams. Descriptions of each icebreaker can be found in the side bar. 


\begin{tabular}{llll} 
Measure & Cond. & Mean & Std Dev. \\
\hline ITS & HS & 14.53 & 2.11 \\
& ST & 15.43 & 2.37 \\
DT & HS & 2632 & 993.47 \\
& ST & 3002 & 475.23 \\
\hline
\end{tabular}

Table 1: Means and standard deviations for Intrateam Trust Scale (ITS) and Daytrader (DT) group payoff. HS = Hollywood Stars, ST = Spaceteam. $\mathrm{N}=40$ for each condition
Daytrader

Daytrader is an iterated Prisoner's Dilemma originally adapted from [3]. It is a mixed-motive game characterized by conflict between the individual and groups best interest [33, 40, 2].

Mixed-motive games are widely used to measure trusting behaviours like cooperation. Group payoff was used as an indicator of behavioural trust.

\section{Communication Medium}

To simulate the virtual work team context, the experiment was conducted over video call via Google Hangouts.

\section{Procedure}

Participants provided informed consent and completed the General Trust Scale before joining the video call on Google Hangouts where they met the rest of their team. During the experiment brief, participants were told to imagine that they were a virtual project team working together for the next six months. The team were told that they had no prior work history and were unlikely to have future work relations after project completion. This brief was meant to frame the experiment in a way that mimicked real-world virtual team conditions.

Each team had two-minutes of free-flow conversation and the experimenter was present throughout the experiment. The study was conducted entirely online. After the freeflow conversation, teams completed the icebreaker activity: Hollywood Stars or Spaceteam. Each condition was approximately 15 minutes. After the activity, participants individually completed the Intrateam Trust Scale. To measure behavioural trust, teams played Daytrader - the game automatically ran until completion. There were 5 rounds in total. Participants were debriefed at the end of the experiment and entered into a $£ 30$ cash prize draw as compensation

\section{Results}

The data were analysed in the Statistical Package for the Social Sciences (SPSS). An independent samples t-test revealed that there was no significant difference in teamlevel disposition to trust across conditions as measured by the GTS, $\mathrm{t}(78)=-1.15, p=.882$. This indicated that teams in both conditions had similar baseline levels of disposition to trust.

H1: Perception of team trust will be positively related to cooperative behaviour

To test Hypothesis 1, data from the ITS were correlated with group payoff in Daytrader using a Pearson correlation analysis. While the analysis revealed a small positive correlation between the dependent variables, it was non-significant $(r=$ $0.11, p=.333$ ). Thus, Hypothesis 1 was not supported.

H2: Teams using Spaceteam will have higher cooperation and higher perception of trust compared to teams using Hollywood Stars.

Table 1 provides means and standard deviations of ITS scores and Daytrader group payoff, separated by condition. An initial inspection of the ITS data showed that the data had no outliers as indicated by a box plot, were normally distributed for each condition as indicated by the ShapiroWilk's test $(p>.05)$, and had homogeneity in variances as indicated by a Levene's test for equality of variances ( $p=$ .419).

An independent samples t-test revealed that there was no significant difference in the ITS scores for the Spaceteam or Hollywood Stars condition, $\mathrm{t}(78)=-1.79, p=.077$. To investigate whether there was a difference in cooperation between the conditions, an independent samples t-test was conducted on the Daytrader group payoff. Group payoff was used as a measure of cooperation because a higher group payoff was only possible when all team members 
cooperated throughout the rounds. A significant main effect of condition on Daytrader group payoff was found such that teams in the Spaceteam condition had significantly higher group payoff than teams in the Hollywood Stars condition, $\mathrm{t}(78)=-2.13, \mathrm{p}=.037$. Thus, Hypothesis 2 was partially supported - teams in the Spaceteam condition have higher cooperation than teams in the Hollywood Stars condition but did not have any difference in perception of team trust.

Hypothesis 3: The effect of Spaceteam on cooperation will not be moderated by an individual's dispositional trust

A hierarchical multiple regression was conducted to test Hypothesis 3 with Daytrader group payoff as the dependent variable. An initial analysis showed evidence of multicollinearity, leading to the independent variables being mean-centered. Variance inflation factor (VIF) scores were calculated for the variables in each regression model to check for multicollinearity. Multicollinearity was found between the interaction variable and condition $(\mathrm{VIF}=4.44)$. According to [1], this can be expected since the interaction variable is a product of the condition variable and can be safely ignored. Hence, we did not expect any adverse consequences. All other VIF scores were below 1.

The hierarchical multiple regression analysis (see Table 2) revealed that Condition contributed significantly to the regression model, $F(1,78)=4.51, p<.05$ and modestly accounted for $6 \%$ of variance in Daytrader group payoff. While the addition of the General Trust Scale and interaction variable explained additional variance, the result did not reach significance. Therefore, Hypothesis 3 was not supported.

\section{Discussion}

This study investigated the effectiveness of a commercial digital game, Spaceteam, in developing trust in virtual teams compared to a social icebreaker. The results

\begin{tabular}{lrrrr} 
Steps and Variables & $\beta$ & $F$ & $R^{2}$ & $\Delta R^{2}$ \\
\hline Step 1: & & & & \\
Condition & $.23^{*}$ & $4.51^{*}$ & .06 & .06 \\
Step 2: & & & & \\
Condition & .23 & & & \\
GTS & .07 & 2.42 & .06 & .01 \\
Step 3: & & & & \\
Condition & .93 & & & \\
GTS & .42 & & & \\
Condition x GTS & -.79 & 2.04 & .07 & .02
\end{tabular}

Table 2: Results of hierarchical multiple regression analysis, $\mathrm{n}=80 .{ }^{*} p<.05$

support an early study [12] and show that a commercial digital game with trust-building aspects is more effective than a social icebreaker, as reflected in the group payoff in Daytrader. This was expected because games with clear shared goals and high interdependence necessitate cooperation for success. Games that present this context have been shown to facilitate social closeness through requiring players to interact and communicate [11, 31]. Through collective planning and strategising [37], combined with instantaneous feedback on behaviour, provided through the game, team members are able to quickly assess trustworthiness. As team members follow through on collective decisions, swift trust beliefs are verified. This in turn influences decisions in future trust-warranting situations like Daytrader.

On the other hand, no differences in perceptions of team trust were found despite the observed behavioural differences. A possible explanation is that team functioning was sustained through swift trust until the end of the experiment. The short time span of the study might not have 
been enough for deeper forms of trust to emerge. Indeed studies showing successful swift trust development have typically observed teams over weeks [22, 36, 9]. Similar patterns have been observed in digital games - deep social bonds are found between players who interact over weeks and months [39]. Future work can investigate the minimum time required for developing swift trust into a deeper form of trust.

In line with [12], we also found no moderating effect of dispositional trust. This can be attributed to the situational strength - the ability of a situation to restrict or encourage certain behaviours [29] - of Spaceteam. Spaceteam provides a 'cooperative social situation' [13, 24] where personal goals can only be achieved if others achieve their goals. This creates a 'strong situation' which influences the expression of dispositional trust. Individuals with lower dispositional trust have to trust and cooperate for their own benefit. Thus, no moderating effect of dispositional trust on Daytrader group payoff was found. This is a positive attribute of trust-building digital games because it implies that their effectiveness applies across team compositions.

\section{Limitations and Future Work}

Although our study has provided new insights, it has several limitations. The study faced technological difficulties where some team members had problems during the video call. This prevented some individuals from fully participating in the tasks and may have negatively biased others' perception of their trustworthiness and reduced perception of team trust. It is also unclear whether communicating via video call has a significant mediating effect on the results of Daytrader. Future work might compare different communication conditions (e.g. no communication, text chat only etc.) to isolate the effect of the game and Daytrader output.
It is also uncertain whether a commercial digital game for trust-building is naturally perceived as valuable by employees without explicit instruction from the organisation. As a controlled experiment, this study could not account for the influence of organisational norms and procedures. A collaboration with an industry partner would benefit future work on the feasibility and effectiveness of commercial digital games in the corporate sector.

Finally, future studies could focus on understanding why digital games are more effective than social ice breakers. Several theories about the action-oriented nature of games has been put forward but which lack direct, empirical support. Future studies might test. This may be better understood by tapping into the perceptions of participants via a follow-up interview study or open-ended survey. Nonetheless, this preliminary study showed that a commercial digital game with trust-building aspects is more effective than a typical virtual team icebreaker at developing trust - a core but elusive component of successful virtual work teams.

\section{Conclusion}

In conclusion, our study highlights a new opportunity for cooperative commercial digital games. Specifically, we provide a guideline for selecting an appropriate commercial digital game for virtual team trust-building (see side bar). We select the commercial mobile game Spaceteam using these guidelines and show that it is effective at building trust between members of 4-person teams. Our findings provide support for the viability of digital games as trust-building tools for virtual work teams. For practitioners, this implies that a trust-building digital game can accelerate the process of swift trust verification. Doing this in a safe environment allows team members to adjust trusting beliefs before engaging in high consequence tasks. For game designers, this study sheds light on the mechanisms thorough which 
gameplay encourages pro-social behaviour

\section{REFERENCES}

1. Paul Allison. 2012. When can you safely ignore multicollinearity. Statistical Horizons 5, 1 (2012).

2. Daniel Balliet. 2010. Communication and cooperation in social dilemmas: A meta-analytic review. Journal of Conflict Resolution 54, 1 (2010), 39-57.

3. Nathan Bos, Judy Olson, Darren Gergle, Gary Olson, and Zach Wright. 2002. Effects of four

computer-mediated communications channels on trust development. In Proceedings of the SIGCHI conference on human factors in computing systems. ACM, 135-140.

4. Aysun Bozanta, Birgul Kutlu, Nuket Nowlan, and Shervin Shirmohammadi. 2012. Multi user virtual environments and serious games for team building Procedia Computer Science 15 (2012), 301-302.

5. Christina Breuer, Joachim Hüffmeier, and Guido Hertel. 2016. Does trust matter more in virtual teams? A meta-analysis of trust and team effectiveness considering virtuality and documentation as moderators. Journal of Applied Psychology 101, 8 (2016), 1151.

6. Emily IM Collins, Anna L Cox, and Frank Lee. 2016. Say Cheese!: Games for Successful Academic and Student Networking. In Proceedings of the 2016 Annual Symposium on Computer-Human Interaction in Play. ACM, 105-115.

7. Jason A Colquitt, Brent A Scott, and Jeffery A LePine. 2007. Trust, trustworthiness, and trust propensity: A meta-analytic test of their unique relationships with risk taking and job performance. Journal of applied psychology 92, 4 (2007), 909.

8. Ana Cristina Costa, C Ashley Fulmer, and Neil R Anderson. 2018. Trust in work teams: An integrative review, multilevel model, and future directions. Journal of Organizational Behavior 39, 2 (2018), 169-184.

9. C Brad Crisp and Sirkka L Jarvenpaa. 2013. Swift trust in global virtual teams. Journal of Personnel Psychology (2013).

10. Bart A De Jong and Tom Elfring. 2010. How does trust affect the performance of ongoing teams? The mediating role of reflexivity, monitoring, and effort. Academy of Management Journal 53, 3 (2010), 535-549.

11. Ansgar E Depping and Regan L Mandryk. 2017. Cooperation and Interdependence: How Multiplayer Games Increase Social Closeness. In Proceedings of the Annual Symposium on Computer-Human Interaction in Play. ACM, 449-461.

12. Ansgar E Depping, Regan L Mandryk, Colby Johanson, Jason T Bowey, and Shelby C Thomson. 2016. Trust me: social games are better than social icebreakers at building trust. In Proceedings of the 2016 Annual Symposium on Computer-Human Interaction in Play. ACM, 116-129.

13. Morton Deutsch. 1949. A theory of co-operation and competition. Human relations 2, 2 (1949), 129-152.

14. Julie Dixon, Heather Crooks, and Karen Henry. 2006. Breaking the ice: Supporting collaboration and the development of community online. Canadian Journal of Learning and Technology/La revue canadienne de lâĂŹapprentissage et de la technologie 32, 2 (2006) 
15. Jason B Ellis, Kurt Luther, Katherine Bessiere, and Wendy A Kellogg. 2008. Games for virtual team building. In Proceedings of the 7th ACM conference on Designing interactive systems. ACM, 295-304.

16. Robert C Ford, Ronald F Piccolo, and Loren R Ford. 2017. Strategies for building effective virtual teams: Trust is key. Business Horizons 60, 1 (2017), 25-34.

17. Marie-Line Germain and David McGuire. 2014. The role of swift trust in virtual teams and implications for human resource development. Advances in Developing Human Resources 16, 3 (2014), 356-370.

18. Lucy L Gilson, M Travis Maynard, Nicole C Jones Young, Matti Vartiainen, and Marko Hakonen. 2015. Virtual teams research: 10 years, 10 themes, and 10 opportunities. Journal of Management 41, 5 (2015), 1313-1337.

19. Penelope Sue Greenberg, Ralph H Greenberg, and Yvonne Lederer Antonucci. 2007. Creating and sustaining trust in virtual teams. Business horizons 50, 4 (2007), 325-333.

20. Henry Smith and Sleeping Beast Games. 2012. Spacteam. Game [mobile]. (November 2012).

21. Carol S lacono and Suzanne Weisband. 1997. Developing trust in virtual teams. In Proceedings of the Thirtieth Hawaii International Conference on System Sciences, Vol. 2. IEEE, 412-420.

22. Sirkka L Jarvenpaa, Kathleen Knoll, and Dorothy $E$ Leidner. 1998. Is anybody out there? Antecedents of trust in global virtual teams. Journal of management information systems 14, 4 (1998), 29-64.

23. Sirkka $L$ Jarvenpaa and Dorothy E Leidner. 1999. Communication and trust in global virtual teams. Organization science 10, 6 (1999), 791-815.
24. David W Johnson, Roger T Johnson, and Geoffrey Maruyama. 1983. Interdependence and interpersonal attraction among heterogeneous and homogeneous individuals: A theoretical formulation and a meta-analysis of the research. Review of educational research 53, 1 (1983), 5-54.

25. Claus W Langfred. 2004. Too much of a good thing? Negative effects of high trust and individual autonomy in self-managing teams. Academy of management journal 47, 3 (2004), 385-399.

26. Roy J Lewicki, Barbara B Bunker, and others. 1996. Developing and maintaining trust in work relationships. Trust in organizations: Frontiers of theory and research 114 (1996), 139.

27. Sheena Lewis, Jason B Ellis, and Wendy A Kellogg. 2010. Using virtual interactions to explore leadership and collaboration in globally distributed teams. In Proceedings of the 3rd international conference on Intercultural collaboration. ACM, 9-18.

28. Roger C Mayer, James H Davis, and F David Schoorman. 1995. An integrative model of organizational trust. Academy of management review 20, 3 (1995), 709-734.

29. Rustin D Meyer, Reeshad S Dalal, and Richard Hermida. 2010. A review and synthesis of situational strength in the organizational sciences. Journal of management 36, 1 (2010), 121-140.

30. Debra Meyerson, Karl E Weick, Roderick M Kramer, and others. 1996. Swift trust and temporary groups. Trust in organizations: Frontiers of theory and research 166 (1996), 195 
31. Benedikt Morschheuser, Marc Riar, Juho Hamari, and Alexander Maedche. 2017. How games induce cooperation? A study on the relationship between game features and we-intentions in an augmented reality game. Computers in human behavior 77 (2017), 169-183.

32. Maaz Nasir, Kelly Lyons, Rock Leung, Anthea Bailie, and Fred Whitmarsh. 2015. The effect of a collaborative game on group work. In Proceedings of the 25th annual international conference on computer science and software engineering. IBM Corp., 130-139.

33. Dean G Pruitt and Melvin J Kimmel. 1977. Twenty years of experimental gaming: Critique, synthesis, and suggestions for the future. Annual review of psychology 28, 1 (1977), 363-392.

34. Catherine M Ridings, David Gefen, and Bay Arinze. 2002. Some antecedents and effects of trust in virtual communities. The Journal of Strategic Information Systems 11, 3-4 (2002), 271-295.

35. Jens Riegelsberger, M Angela Sasse, and John D McCarthy. 2005. The mechanics of trust: A framework for research and design. International Journal of Human-Computer Studies 62, 3 (2005), 381-422.

36. Lionel P Robert, Alan R Denis, and Yu-Ting Caisy Hung. 2009. Individual swift trust and knowledge-based trust in face-to-face and virtual team members. Journal of Management Information Systems 26, 2 (2009), 241-279.

37. Eduardo Salas, Heather A Priest, and Renée E DeRouin. 2004. Team building. In Handbook of human factors and ergonomics methods. CRC Press, 491-496.

38. Tony L Simons and Randall S Peterson. 2000. Task conflict and relationship conflict in top management teams: The pivotal role of intragroup trust. Journal of applied psychology 85, 1 (2000), 102.

39. Dmitri Williams, Nicolas Ducheneaut, Li Xiong, Yuanyuan Zhang, Nick Yee, and Eric Nickell. 2006.

From tree house to barracks: The social life of guilds in World of Warcraft. Games and culture 1, 4 (2006), 338-361.

40. Toshio Yamagishi, Satoshi Kanazawa, Rie Mashima, and Shigeru Terai. 2005. Separating trust from cooperation in a dynamic relationship: prisonerâǍźs dilemma with variable dependence. Rationality and society 17, 3 (2005), 275-308.

41. Toshio Yamagishi and Midori Yamagishi. 1994. Trust and commitment in the United States and Japan. Motivation and emotion 18, 2 (1994), 129-166.

42. Jun Zheng, Elizabeth Veinott, Nathan Bos, Judith $S$ Olson, and Gary M Olson. 2002. Trust without touch: jumpstarting long-distance trust with initial social activities. In Proceedings of the SIGCHI conference on human factors in computing systems. ACM, 141-146.

43. Roxanne Zolin, Renate Fruchter, and Pamela J Hinds. 2003. Communication, trust and performance: The influence of trust on performance in $\mathrm{A} / \mathrm{E} / \mathrm{C}$ cross-functional, geographically distributed work. (2003). 